\title{
Employee Payroll And Training Budget: Case Study Of A Non-Teaching Healthcare Organization
}

Ishtiaq Ahmed, SZABIST University, Pakistan

Nadir Ali Kolachi, Skyline University, UAE

\begin{abstract}
Employee turnover is a constant phenomenon faced by organizations. Some turnover is not only healthy, but also necessary for an organization, as it allows for an influx of new blood; however, high levels of turnover can be unhealthy for an organization. This study aims to calculate the employee turnover rate in a particular healthcare organization and compare it with the benchmarks provided in existing literature, and to discover potential reasons for the organization's high turnover. Available data from previous years were also analyzed to estimate the financial and non-financial losses of the organization. The study addresses and rates the importance of some of the most common factors that determine the overall satisfaction of employees, such as salary and other benefits, career opportunity and personal growth, and work life protocols, including policies and procedures, working environment conditions, supervisor behavior, and colleague behavior and support. The results of this research will be helpful for not only the healthcare industry, but also the overall corporate sector, because turnover can pose a serious problem and therefore needs to be promptly investigated and resolved.
\end{abstract}

Keywords: Turnover Rate; Healthcare; Non-Teaching

\section{INTRODUCTION}

\section{Background}<smiles>O</smiles>

mployee retention is the primary concern of organizations. Although human capital is not clearly reflected in most financial balance sheets, human capital determines whether these balance sheets are positive or negative. High-performing human capital can change a loss-making organization into a profitable one; however, there are many opportunities in the market for high performers, and organizations must work hard to retain such employees to ensure their own growth and, in some cases, survival. It is a fact that healthy employee turnover is necessary for organizations because it prevents them from becoming stagnant. If there is no employee turnover, an organization will struggle in terms of introducing innovative business ideas and improving business processes. Moreover, for organizations that are unwilling to horizontally or vertically expand their businesses, employee turnover is a particularly important source of innovation, with new employees serving as creative resources. To enjoy the benefits of healthy employee turnover, organizations should not be rigid or inflexible. They should be ready to consider and implement the ideas of new employees and welcome innovation. However, unhealthy employee turnover can be damaging for an organization, causing not only direct financial losses but also indirect sustained financial losses. A case study approach was employed and the reasons for employee turnover in a non-teaching healthcare organization were determined.

\section{Organization Overview}

The non-teaching healthcare organization considered in this study is a part of the healthcare industry and was established two decades ago as a private limited company. It is situated in the heart of Karachi, which is the 
economic hub of Pakistan. On average, it has 450 employees, including medical, paramedical, and administrative staff. Although a large majority of its employees are employed on a permanent basis, approximately $10 \%$ are employed on a contractual basis. The organization is famous for the high quality of its services, especially its nursing care. It also employs a consultant-based medical practice, involving outside consultants who have formal contracts as independent contractors. Outpatient clinics are situated on the organization's premises. Initially, the organization offered specialized medical care; however, it soon developed into a general hospital.

\section{Research Problem, Objectives \& Scope Of The Study}

High employee turnover is a problem commonly faced in the corporate world. It affects organizations not only directly, but also indirectly, because it possesses accompanying and hidden after-effects that can cause harm unexpectedly. If these effects are not considered when turnover begins to become a problem, it can be the major cause of collapse for the affected organization. This study investigates the reasons for employee turnover in a particular organization, based on a very reliable and important tool - an exit interview questionnaire filled out by employees leaving the company. To address the problem, some objectives were kept in mind as to calculate the organization's employee turnover rate, identify the reasons for employee turnover in the organization, identify whether there are any areas of the organization that are highly affected by turnover, and to provide the organization with the opportunity to minimize any financial and non-financial costs arising because of employee turnover. Since employee turnover and retention of employees is a common dilemma for organizations, this case study will be significant not only in the field of healthcare but also in other industries. It will address important dimensions of turnover that should be considered while preparing employee-related policies, especially by executives and human resource managers. The study was conducted on a service-oriented healthcare organization. However, the results of this study can be extended to the service industry and other healthcare organizations. This study may be a milestone for further research on the issue of employee turnover and could provide recommendations to researchers and human resource professionals.

\section{LITERATURE REVIEW}

\section{Importance of Employee Turnover}

Barnett (1995) explained that there are two types of employee turnover - forced and voluntary. Companies facing considerable employee turnover, which is problematic, are typically concerned about voluntary employee turnover. Khatri, Budhwar, and Fern (n.d.) indicated that executives of companies are concerned about high employee turnover throughout the world. However, there is a particular need for conducting employee turnover studies in Asia. There are many reasons for employee turnover and, although some of them are controllable, others are uncontrollable. Some of the reasons can be identified through studies that permit associated losses to be controlled and overcome. Morrell, Loan-Clarke, and Wilkinson (2004) emphasized the direct and indirect financial impacts of employee turnover in organizations. They also explained how turnover can lead to organizational change when it is not handled appropriately, presenting a universal challenge for organizations. No single factor is primarily responsible for employee turnover and these factors vary according to the situation.

WeiBo, Kaur, and Zhi (2010) regarded human talent as the intellectual property of an organization and if it is not managed appropriately, organizations may lose this property for many reasons. Leaving intellectual property unattended is harmful to an organization and can create difficulties, especially when employee turnover is high. Intellectual property is actually a form of social capital, which is more important than the material assets or financial capital of organizations. Chen et al. (2010) suggested that well-developed employees are the backbone of a company, especially in the service industry. Currently, our economy is knowledge-based and employees will continue to search for better employment and career opportunities, if they are available. High employee turnover, particularly in the service industry, can weaken the organization's profitability and unexpectedly harm the organization in different ways. 


\section{Reasons for Employee Turnover}

Hamori, Cao, and Koyuncu (2012) conducted research on over 1,200 employees through online surveys, personal interviews, and analyses of large international databases. They concluded that young high performers (30years old, on average), who have a good academic record and considerable experience and who are satisfied with company engagement programs, change jobs after every 28 months, on average. The driving factor of this job change is that these young high performers hope to receive a major increase in salary upon changing jobs, because they cannot receive such an increase in the same organization in the near future. In cases of dissatisfaction, however, employees typically leave their jobs earlier than 28 months. Reasons for dissatisfaction may include a lack of training, on-the-job mentoring, or coaching. Usually, employers do not invest in developing their employees because they are concerned that it will lead them to quit; however, employees often leave their jobs because they are not being trained or developed in their existing roles. Moreover, Hamori, Cao, and Koyuncu (2012) found that young high performers and energetic employees regularly search for new jobs and also use their networks for this purpose.

Groysberg \& Abrahams (2010) emphasized that executives occasionally make inappropriate decisions while switching their jobs, and such decisions negatively influence their professional careers. They referred to the US Bureau of Labor Statistics' findings that professionals, on average, change jobs 10 times throughout their careers. Their usual reasons for switching jobs are for a considerable raise in pay or because of their level of dissatisfaction with their current job. Groysberg and Abrahams (2010) also stated that people occasionally leave their current positions without conducting sufficient research on the market and other companies, and therefore build up high expectations that lead them to prefer switching jobs to staying in the same position. Occasionally, people feel that they do not fit in their current organizational culture, so therefore they choose to change jobs. Some employees are either unhappy or dissatisfied with their current role definition; therefore, they search for a title that is better aligned with their ideal job description. In other cases, people get so frustrated with their current employer and want to leave immediately, leading them to leave without considering where they are going, thus selecting the first available job opportunity. Ali (2008) conducted a questionnaire research among private sector college lecturers in D.I. Khan, NWFP, Pakistan and revealed that factors increasing turnover rates, influencing job satisfaction, and initiating the intention to switch jobs include salary, career growth, management, compensation and benefits, working conditions, nature of work, colleagues' behavior, and communication within the organization.

Chen et al. (2010) proposed that there are four main factors that contribute to the retention or leaving of employees in the hospitality industry: 1) career opportunities available at the organization, 2) mentoring programs for employees, 3) organizational communication policy, and 4) salary and other benefits. High employee turnover ratios are more dangerous in service industries than in manufacturing concerns. Chen et al. (2010) related employee satisfaction to retention ratios and focus on employee satisfaction and retention in the service industry.

Van et al. (2004) used the terms "pull" and "push" to address employee turnover. Pull refers to the career opportunities available in an organization that employees can use to enhance their careers which, in turn, retain employees, pull their employment in the organization, and give the organization a competitive advantage. Push refers to factors that compel employees to leave an organization based on their perception that their current job is a hurdle in their careers.

George and Jones (1996) argued that factors which considerably influence job satisfaction and lead to employee turnover include supervision style, role clarification, independence of work, employee engagement, and the availability of moral and social support.

Hammerberg (2002) conducted a study to discover the reasons for employee turnover in departmental stores and indicated that temporary employees may leave their jobs simply because it is easy for them to switch jobs and gain new employment; that is, because of non-job-related issues. However, permanent employees tend to leave because of working conditions, conflict with their immediate boss, working schedule issues, and dissatisfaction with compensation and benefits. Hammerberg (2002) conducted research from June 1, 1999 to September 30, 1999, using a questionnaire given to 1,190 exiting employees of 53 departmental stores in the USA. The findings showed that $381(32 \%)$ employees left the organization during their first three months of employment tenure, 425 (35.7\%) left after four months to a year of employment, 185 (15.5\%) left after one to two years of employment, $190(16.0 \%)$ 
after more than two years of employment, and for 9 employees $(0.8 \%)$, the data was missing. This study also found that $57.2 \%$ of respondents left their organizations either without notice or for personal reasons. The highest number of employees left their jobs (37.4\%) for job-related reasons, $29.4 \%$ left for non-job-related reasons, $16.6 \%$ left without any prior notice, $8.5 \%$ were terminated for making mistakes, $3.6 \%$ left due to abandonment, and $3.6 \%$ left for miscellaneous reasons.

According to the Society for Human Resource Management (SHRM) database (2011), employees generally voluntarily separate from organizations based on dissatisfaction with their current job, misalignment with their supervisors, a lack of career opportunities, the availability of better opportunities, and cultural or structural changes in their current organizations. In contrast, forced separations based on the will of the employer may be owing to dayto-day changes in economic conditions or business market situations in the country.

Jaffari et al. (2011) conducted a study on the banking sector of Pakistan and found that compensation and benefits, career growth in the current organization, satisfaction with current job role, job switching intention, availability of better opportunities, and alignment with their bosses or supervisors are the common reasons for employees to leave an organization, especially during periods when their industry is in peak economic condition or has positive potential for growth. During such periods, career growth and the existence of other available opportunities are the primary reasons of employee turnover.

\section{Turnover Rates}

The Society for Human Resource Management (2011) investigated the expected turnover and hiring vacancies in various industries in the US in 2010 and provided the following findings:

\section{Industries}

Services: Accommodation, Food, and Drinking Places

Arts, Entertainment, and Recreation

Retail/Wholesale Trade

High-Tech

Government Sector

Association: Professional/Trade

Utilities

All Industries

\author{
$\underline{\text { Average Annual Turnover }}$ \\ $35 \%$ \\ $27 \%$ \\ $22 \%$ \\ $11 \%$ \\ $9 \%$ \\ $8 \%$ \\ $8 \%$ \\ $15 \%$
}

Another survey, which was conducted in Florida from July to September 2009 among hospitals (Workforce Demand in Nursing-Intensive Healthcare Settings, 2010), aimed to project nursing needs in the coming year and found that the turnover rates among nurses were as follows:

\section{Nursing Category}

Registered Nurses

Hospice Nurses

Home Care Nurses

Licensed Practical Nurses (LPNs)

Certified Nursing Assistants (CNAs)

Psychiatric Certified Nursing Assistants (PCNAs)

\author{
$\underline{\text { Turnover Rate }}$ \\ $6.8 \%$ \\ $7.0 \%$ \\ $8.6 \%$ \\ $8.8 \%$ \\ $6.7 \%$ \\ $8.9 \%$
}

A survey that was conducted in 2009 in New York City by The Healthcare Association of New York State (2010), involving 118 hospitals and healthcare organizations, calculated the employee turnover rates in the healthcare sector as follows:

\section{Category}

Licensed Clinical Social Workers (LCSWs)

Dieticians

Coders
Turnover Rate

12.5

$9.1 \%$

$6.4 \%$ 
Physician Therapists (PTs)

Clinical Laboratory Technicians

Rad Technicians

Pharmacists

Nurse Practitioners (NPs)

Physician Assistants (PAs)

Certified Nursing Assistants (CNAs)

Licensed Practical Nurses (LPNs)

All Staff
$9.7 \%$
$6.6 \%$
$5.8 \%$
$6.8 \%$
$6.8 \%$
$8.9 \%$
$10.9 \%$
$10.6 \%$
$9.6 \%$

The HSM Group (2002) conducted a study to calculate the benchmarks of employee turnover in 693 healthcare organizations during July and August 2001. The turnover rates for registered nurses (RNs) were found to be as follows:

\section{Category}

Large Hospitals (350+ beds)

Specialty Hospitals

Other Hospitals

National Average

\section{Turnover Rate}

$17.1 \%$

$25.2 \%$

$10 \%-30 \%$

$21.3 \%$

Hayajneh et al. (2009) conducted a survey among hospitals in Jordan and found that the turnover rate among RNs was as follows:

\section{Category}

Female Nurses

Male Nurses

Northern Areas of Jordan

Middle Areas of Jordan

Southern Areas of Jordan

Government Hospitals

Private Hospitals

Teaching Hospitals (University/College)

Urban Areas of Jordan

Rural Areas of Jordan

General Hospitals

Specialized Hospitals

Overall Turnover Rate among Registered Nurses

\section{Turnover Rate}

$36.2 \%$

$37.0 \%$

$31.3 \%$

$39.8 \%$

$21.8 \%$

$29.5 \%$

$66.7 \%$

$33.0 \%$

$39.9 \%$

$28.8 \%$

$36.6 \%$

$37.8 \%$

$36.6 \%$

The Hawaii AIDS Education and Training Center AIDS Education Project (n.d.) found that the turnover of doctors in the USA ranged between $10 \%$ and $15 \%$.

Hayajneh et al. (2009; cited in American Nurses Association, 1962) indicated that an employee turnover rate of $40 \%$ among nurses was unacceptable. The Australian Ministerial Taskforce (1998) reported that between 1994 and 1998, the average employee turnover rate among nurses in Australia was 20.2\%. Gray (n.d.) regarded the nurse turnover rates of $15.4 \%$ in the UK as high. Nursing turnover rates in Ireland were 52\% in 1990, 29\% in 1991, and $22 \%$ in 1992. The Health Foundation of Greater Cincinnati (2008) reported that physician turnover rates in the United States are as follows:

\section{$\underline{\text { Region }}$}

Central

West

East $\underline{\text { Turnover Rate }}$

$7.0 \%$

$6.7 \%$

$6.5 \%$ 


\section{RESEARCH METHODOLOGY}

This study is based on qualitative data. The primary data were collected through a questionnaire and nonstructured interviews with exiting employees. Questionnaires used Likert scale questions to rate variables and were filled out by employees leaving the organizations at times that were convenient to them. Available existing data were also considered to better understand the situation.

\section{Data Analysis Tools \& HR Comments}

Available data on past employees and the data collected thorough questionnaires that were answered by leaving employees were analyzed using MS Excel and SPSS.

Managers and other employees of the non-teaching healthcare organization were interviewed informally regarding the organization's problem with employee turnover. Generally, most interviewees expressed their concern regarding the situation and the trouble involved in high employee turnover. The departmental managers were tired of training new employees and were unaware of the exact reason causing employee turnover. They all appreciated the research objectives, hoped that this study would be useful, and expressed their commitment to helping with the study.

In an interview conducted on 13 August, 2012 with Ehsan ul Haq, the HR manager at ZIL Limited said that employee turnover is a dilemma that exists in the corporate world and poses a challenge for human resource managers. It can involve unrealized losses and have highly unpredictable effects on the overall performance of an organization. Its causes and outcomes are non-static and change rapidly with time. This study will be helpful not only for the healthcare organizations, but also for other organizations in the corporate world.

\section{CONCEPTUAL FRAMEWORK FOR EMPLOYEE SATISFACTION}

Following is the research framework as shown in Table 1.

Table 1: Conceptual Framework

\begin{tabular}{|l|c|}
\hline Salary \& Other Benefits & Overall Working Experience \\
\hline Career Opportunities \& Personal Growth & (Satisfaction) \\
\hline Work Life Protocols, Policies, \& Procedures & \\
\hline Working Environment & \\
Relationship with Supervisors & \\
\hline Colleagues’ Behavior \& Support & \\
\hline
\end{tabular}

\section{DATA ANALYSIS \& DISCUSSION}

\begin{tabular}{|c|c|c|c|}
\hline Year & Average No. of Employees & No. of Exiting Employees & Turnover Rate \\
\hline 2008 & 440 & $\overline{252}$ & $57 \%$ \\
\hline 2009 & 434 & 284 & $65 \%$ \\
\hline 2010 & 433 & 265 & $62 \%$ \\
\hline 2011 & 464 & 207 & $45 \%$ \\
\hline
\end{tabular}

\section{Explanation}

Employee turnover rates were based on the total number of employees leaving the organization during a given year divided by the monthly average employees on board and multiplied by 100 . Table \#1 indicated that in 2008, 252 employees left the organization. If we divide this by the average monthly employees on board (440), we get a turnover rate of $57 \%$. By employing the same formula for the subsequent years, we can see that in 2009 , the employee turnover rate was 65\%; in 2010, it was 61\%; and in 2011, it was $45 \%$. Existing literature suggests that employee turnover rates hovering between $10 \%$ and $15 \%$ can be considered healthy and that rates above that range represent high employee turnover. Therefore, it is evident that this organization is facing an alarming situation that 
should be addressed immediately to prevent unacceptable and uncontrollable situations. Even the finding that the turnover rate declined in the year 2011 from past years should be viewed in light of the overall economic and employment conditions in Pakistan, which have worsened. Although the overall employee turnover rate has fallen by approximately $50 \%$ in the overall country, it continues to be very high. A very reliable survey conducted by a multinational surveyor agency in 2010 showed that the employee turnover rate of different industries in Karachi, Pakistan, was $10.4 \%$, whereas in 2011, the same survey found a turnover rate of $5.6 \%$. The reason for this decline was found to be the non-availability of employment, economic conditions of the country, instability in the business world, and unsatisfying overall market factors (the name of the surveyor company has deliberately not been cited here). The employee turnover rate in the organization addressed in this study hovered around $50 \%$ or more during the period 2008-2011, which shows that more than half of the employees were replaced during most years. This could cause serious financial issues for the organization. Therefore, this study subsequently analyzed the data in segments to determine how long employees stayed in the organization and what problems led them to leave the organization.

Of the employees who left the organization, $13 \%$ left within one month of employment, $28 \%$ left after working one month but before three months, $13 \%$ left between four and six months, $11 \%$ left between seven and nine months, $3 \%$ left after completing nine months but before twelve months, and $32 \%$ completed one year or more before leaving. In 2009, 35\% of employees completed one year or more before leaving, $1 \%$ completed six months but less than a year, $7 \%$ completed six to nine months, $11 \%$ completed three to six months, $22 \%$ completed one to three months, and, surprisingly, 23\% did not even complete one month. The separation records of the organization state that $26 \%$ of the employees leaving the company did so within one month of employment, $23 \%$ left between one and three months, $13 \%$ left between three and six months, $7 \%$ left after seven to nine months, 3\% left after nine months to one year, and $28 \%$ left after one year or more. In this organization, the initial six months of employment are considered to represent the learning period for newcomers and constitute the probationary period in which new employees receive work training, learn the systems and procedures of the organization, and gain familiarity with its culture. Probationary employees are paid and have access to the organization's resources, which implies that if they leave the organization before completing six months, they essentially receive training at the cost of the employer and this training will benefit other organizations, particularly competitors. Therefore, the organization could be seen as paying for training competitors' employees, particularly given the high turnover rate prior to the end of the probationary period. This emphasizes how important it is for the organization to retain human capital.

The average salary of employees during the period 20080-2010 was as follows:

$\begin{array}{ll}\frac{\text { Year }}{2008} & \text { Monthly Average Salary } \\ 2009 & 14,000 \\ 2010 & 14,500 \\ & 15,000\end{array}$

Multiplying the average monthly salary by the total number of employees leaving the organization before the completion of six months of employment yields the average losses of the organization:

$\begin{array}{lc}\frac{\text { Year }}{2008} & \text { Average Salary Paid to Employees Leaving before Six Months of Employment } \\ 2009 & 4,508,000 \\ 2010 & 4,618,250 \\ \text { Total } & \underline{4,972,500} \\ & 14,098,750\end{array}$

The above figures on financial losses do not include the organization's losses in terms of resources and direct and indirect facility use.

Table 2 shows the departmental employee turnover. 
Table 2: Departmental Employee Turnover

\begin{tabular}{|c|c|c|c|}
\hline \multirow[t]{2}{*}{ Department } & \multicolumn{3}{|c|}{ Department Turnover Rates by Year } \\
\hline & 2008 & 2009 & 2010 \\
\hline Accounts & $35 \%$ & $44 \%$ & $32 \%$ \\
\hline Administration * & $55 \%$ & $15 \%$ & $43 \%$ \\
\hline Billing & $0 \%$ & $61 \%$ & $71 \%$ \\
\hline Cardiac & $13 \%$ & $40 \%$ & $48 \%$ \\
\hline Communication & $73 \%$ & $120 \%$ & $23 \%$ \\
\hline Dietician & $0 \%$ & $96 \%$ & $171 \%$ \\
\hline Front Office: Floor Co-Ord. & $97 \%$ & $102 \%$ & $78 \%$ \\
\hline Front Office: Front Desk Exe. & $149 \%$ & $89 \%$ & $104 \%$ \\
\hline Housekeeping: Watchmen & $49 \%$ & $34 \%$ & $51 \%$ \\
\hline Housekeeping: Sweepers & $87 \%$ & $50 \%$ & $19 \%$ \\
\hline Housekeeping: Ward Asst. & $81 \%$ & $60 \%$ & $61 \%$ \\
\hline HR & $0 \%$ & $0 \%$ & $32 \%$ \\
\hline IT & $33 \%$ & $56 \%$ & $13 \%$ \\
\hline ICU: Medical Officers & $51 \%$ & $55 \%$ & $112 \%$ \\
\hline ICU: Nurses \& Technicians & $25 \%$ & $98 \%$ & $48 \%$ \\
\hline Laboratory & $42 \%$ & $31 \%$ & $25 \%$ \\
\hline Linen & $23 \%$ & $35 \%$ & $112 \%$ \\
\hline Medical: Medical Officers & $78 \%$ & $210 \%$ & $200 \%$ \\
\hline NICU: Nurses, Tech. & $19 \%$ & $83 \%$ & $0 \%$ \\
\hline Nursing: Ward & $70 \%$ & $108 \%$ & $79 \%$ \\
\hline OPD/ER & $57 \%$ & $37 \%$ & $132 \%$ \\
\hline OBS/Gyn. & $103 \%$ & $152 \%$ & $164 \%$ \\
\hline Operation Theatre & $46 \%$ & $61 \%$ & $42 \%$ \\
\hline Pharmacy & $18 \%$ & $36 \%$ & $55 \%$ \\
\hline Physiotherapy & $100 \%$ & $0 \%$ & $0 \%$ \\
\hline Radiology: Nurses, WPOs, etc. & $9 \%$ & $81 \%$ & $81 \%$ \\
\hline Transport: Drivers & $59 \%$ & $32 \%$ & $39 \%$ \\
\hline
\end{tabular}

The department turnover rates indicated in Table 2 elucidate that some departments are facing extraordinarily high turnover. Rates above $100 \%$ show that within just one year all the employees in the department had left the organization and had been replaced, and this is the case for floor coordinators in the front office, ICU medical officers, medical officers in medical wards, and members of the Nursing, Gynecology, and Obstetrics departments. These high rates represent a clear employee turnover problem that needs to be addressed. In $2011,50 \%$ of the employees left the organization before completing six months of employment and $43 \%$ left between six months and three years. Only $8 \%$ of the employees who left had completed three years with the organization.

Table 3 shows employee turnover in percentages.

Table 3: Employee Turnover

\begin{tabular}{|l|c|}
\hline \multicolumn{1}{|c|}{ Department Name } & Turnover Rate \\
\hline Accounts & $17 \%$ \\
\hline Administration & $13 \%$ \\
\hline Billing & $30 \%$ \\
\hline Communication & $68 \%$ \\
\hline Cardiac & $15 \%$ \\
\hline Dietician & $0 \%$ \\
\hline Front Office & $45 \%$ \\
\hline Housekeeping & $30 \%$ \\
\hline HR & $0 \%$ \\
\hline ICU & $37 \%$ \\
\hline IT & $32 \%$ \\
\hline Laboratory & $30 \%$ \\
\hline Linen & $86 \%$ \\
\hline
\end{tabular}




\begin{tabular}{|l|c|}
\hline Medical Ward & $141 \%$ \\
\hline NICU & $0 \%$ \\
\hline Nursing & $55 \%$ \\
\hline Obstetric/Gyn. & $80 \%$ \\
\hline OPD & $45 \%$ \\
\hline OT/OR & $43 \%$ \\
\hline Physiotherapy & $0 \%$ \\
\hline Pharmacy & $97 \%$ \\
\hline Transport & $54 \%$ \\
\hline X-Ray & $52 \%$ \\
\hline
\end{tabular}

Table 3 shows that medical officers (MOs) in the Medical Ward, Nursing, Housekeeping, Front Office, and Pharmacy departments are the most highly affected by employee turnover. It should be considered that the operational areas of these staff members are the same. To determine the reason for the high employee turnover, an exit interview questionnaire was administered to employees leaving the organization and they were personally interviewed whenever possible. They were asked what their main reasons were for leaving and they were permitted to select more than one option, rating each variable on a Likert scale. The data collected over a period of six months during 2012 are represented in Tables 4 (Respondent Department 1) and 5 (Respondent Department 2).

Table 4: Respondent Department 1

\begin{tabular}{|c|c|c|c|c|c|c|c|c|}
\hline \multirow{2}{*}{$\begin{array}{l}\text { S. \# } \\
1\end{array}$} & \multicolumn{2}{|c|}{ Respondent Department } & \multirow{2}{*}{$\begin{array}{c}\begin{array}{c}\text { Opportunities } \\
\text { \& Career } \\
\text { Growth }\end{array} \\
2 \\
\end{array}$} & \multirow[t]{2}{*}{ Education } & \multirow[t]{2}{*}{$\begin{array}{c}\text { Salary \& } \\
\text { Other Benefits }\end{array}$} & \multirow[t]{2}{*}{$\begin{array}{l}\text { Personal } \\
\text { Reasons }\end{array}$} & \multirow[t]{2}{*}{ Workload } & \multirow[t]{2}{*}{ Rotation } \\
\hline & Accounts & 2 & & & & & & \\
\hline 2 & Administration & 1 & & & 1 & & & \\
\hline 3 & Billing & & & & & & & \\
\hline 4 & Cardiac & 1 & & & 1 & & & \\
\hline 5 & Communication & & & & & & & \\
\hline 6 & Front Office & 11 & 3 & 5 & 3 & 3 & & \\
\hline 7 & Housekeeping & 20 & 1 & & 2 & 7 & 3 & \\
\hline 8 & ICU & & & & & & & \\
\hline 9 & IT & 1 & 1 & & & & & \\
\hline 10 & Laboratory & 4 & 1 & 2 & & 1 & & \\
\hline 11 & Linen & 2 & 1 & & & & & \\
\hline 12 & Medical Ward & 10 & 3 & 6 & 1 & 1 & 3 & 3 \\
\hline 13 & Nursing & 9 & 3 & & 1 & 3 & & \\
\hline 14 & OBS & 1 & & & & & & \\
\hline 15 & OPD & & & & & & & \\
\hline 16 & OT & 4 & & 1 & 1 & 1 & & \\
\hline 17 & Pharmacy & 6 & 1 & 1 & 2 & 3 & & \\
\hline 18 & Transport & 5 & 1 & & 1 & & & \\
\hline 19 & X-Ray & 2 & 1 & 1 & & & & \\
\hline \multicolumn{2}{|c|}{ Total } & 79 & 18 & 16 & 13 & 19 & 6 & 3 \\
\hline \multicolumn{3}{|l|}{$\%$} & $23 \%$ & $20 \%$ & $16 \%$ & $24 \%$ & $8 \%$ & $4 \%$ \\
\hline
\end{tabular}

Table 5: Respondent Department 2

\begin{tabular}{|l|l|c|c|c|c|c|c|c|}
\hline S. \# & \multicolumn{2}{|l|}{ Respondent Department } & $\begin{array}{c}\text { Duty } \\
\text { Hours }\end{array}$ & $\begin{array}{c}\text { Company } \\
\text { Policies }\end{array}$ & $\begin{array}{c}\text { Working } \\
\text { Environment }\end{array}$ & $\begin{array}{c}\text { Relationship } \\
\text { with } \\
\text { Supervisor }\end{array}$ & $\begin{array}{c}\text { Relationship } \\
\text { with Colleagues }\end{array}$ & $\begin{array}{c}\text { Forced } \\
\text { Separation }\end{array}$ \\
\hline 1 & Accounts & 2 & & & & & & \\
\hline 2 & Administration & 1 & & & & & & \\
\hline 3 & Billing & & & & & & & \\
\hline 4 & Cardiac & 1 & & & & & & \\
\hline 5 & Communication & & & & & & & \\
\hline 6 & Front Office & 11 & 1 & & & & & \\
\hline 7 & Housekeeping & 20 & & & & & & 1 \\
\hline 8 & ICU & & & & & & & \\
\hline
\end{tabular}




\begin{tabular}{|c|c|c|c|c|c|c|c|c|}
\hline 9 & IT & 1 & & & & & & \\
\hline 10 & Laboratory & 4 & & & & & & \\
\hline 11 & Linen & 2 & & & & & & 1 \\
\hline 12 & Medical Ward & 10 & 1 & & 1 & 1 & & \\
\hline 13 & Nursing & 9 & & & & & & 2 \\
\hline 14 & OBS & 1 & & & & & & \\
\hline 15 & OPD & & & & & & & \\
\hline 16 & OT & 4 & & & & & & 1 \\
\hline 17 & Pharmacy & 6 & & & & & & 2 \\
\hline 18 & Transport & 5 & & & & 1 & & 3 \\
\hline 19 & X-Ray & 2 & & & & & & 1 \\
\hline \multicolumn{2}{|c|}{ Total } & 79 & 2 & $\mathbf{0}$ & 2 & 2 & 2 & 22 \\
\hline \multicolumn{2}{|c|}{$\%$} & & $3 \%$ & $0 \%$ & $3 \%$ & $3 \%$ & $3 \%$ & $28 \%$ \\
\hline
\end{tabular}

A total of 85 employees left the organization during the study period of six months, out of whom 79 filled out the exit interview form, yielding a response rate of $92 \%$. The respondents' primary reasons for leaving were career growth $(23 \%)$, further education (20\%), salary and other benefits (16\%), forced separation (28\%), and personal reasons $(24 \%)$.

\section{RESULTS \& CONCLUSION}

We found that the employee turnover rate in this non-teaching healthcare organization is extraordinarily high and needs to be reduced immediately. A lack of career growth was found to be a problem for the Accounts, Front Office, Medical Ward, and Nursing departments. Members of the Laboratory, Front Office, and Medical Ward departments stated that they were leaving due to a desire to pursue further education. To address this, employees should be given more downtime so that they are able to continue with their education while being employed. Forced separation should also be reduced. Members of the Front Office, Housekeeping, and Pharmacy departments were found to leave the organization because of their low salaries. Personal reasons were also found to be a major cause of employee loss across departments. In personal interviews with employees, many mentioned that they were leaving the organization because of the bad behavior of their supervisors and colleagues; however, they felt hesitant to mention this in writing and therefore indicated personal reasons for leaving in the questionnaire. Some also chose education or opportunities for career growth when, in fact, their actual reasons were related to the behavior of their supervisors or coworkers.

\section{RECOMMENDATIONS}

- $\quad$ To provide career opportunities within the organization, it should be made into a teaching organization because doctors and nursing staff prefer hospitals providing post-graduate study programs that enhance their skills and career growth. Managers and staff should be provided with behavioral training for educating them on appropriate ways of behaving with subordinates and colleagues.

- New employees should go through a proper orientation process. The current culture of the organization should be transitioned into a performance-based culture; that is, a culture that rewards performance rather than seniority alone. New ideas and creativity should be welcomed by supervisors. A salary revision for employees in the Front Office, Housekeeping, and Pharmacy Departments should be considered.

\section{LIMITATIONS OF THE STUDY}

This study only considers one non-teaching healthcare organization. The study time was limited.

\section{AUTHOR INFORMATION}

Mr. Ishtiaq Ahmed is working as visiting faculty at SZABIST University, Karachi, Pakistan. Mr. Ishtiaq has also worked in various corporations at the middle hierarchy of the companies in Pakistan. He is also pursuing his PhD in Management Sciences. He has also done few independent case studies for the purpose of his MS studies in Management Sciences. 
Dr. Nadir Ali Kolachi is an Associate Professor at Skyline University, University City of Sharjah, UAE. He has more than fifteen years of training, teaching, consultancy, and research experience at National \& International levels. Dr. Kolachi has earned an MBA, MS and Ph.D. in Management. He has delivered many keynote speeches \& research presentations on Management, HR, HRD, Change Management, OD, Management Education, Public Administration, Corporate Leadership and Organizational Communication in the USA, UK, Poland, Italy, Portugal, Pakistan, India and UAE. He is a Certified Corporate trainer of GAMMP International (Global Association of Management \& Marketing Professionals). E-mail: nadir.kolachi@skylineuniversity.ac.ae (Corresponding author)

\section{REFERENCES}

1. Naresh Khatri, Pawan Budhwar, and Chong Tze Fern, n.d., "Employee turnover: Bad Attitude or Poor Management?," viewed on 13 August 2012, http://www3.ntu.edu.sg/nbs/sabre/working_papers/12-99.pdf

2. Kevin M. Morrell, John Loan-Clarke, and Adrian J. Wilkinson, 2004, "Organisational Change 2012 http://www98.griffith.edu.au/dspace/bitstream/handle/10072/16835/?sequence=1

3. Zheng WeiBo, Sharan Kaur, and Tao Zhi, 2010, "A Critical Review of Employee Turnover Model (19382009) and Development in Perspective of Performance," African Journal of Business Management, Vol. 4, No. 19, pp. 4146-4158, December Special Review, 2010, Viewed on 13 August, 2012, http://www.academicjournals.org/ajbm/pdf/pdf2010/29Dec/Zheng\%20et\%20al.pdf, ISSN 1993-8233

4. Monika Hamori, Jie Cao, and Burak Koyuncu, 2012, "Why Top Young Managers Are in a Nonstop job Hunt," Harvard Business Review, July-August, p. 28.

5. Boris Groysberg and Robin Abraham, 2010, "Five Ways to Bungle a Job Change," Harvard Business Review, January-February, p. 137.

6. Nazim Ali, 2008, "Factors Affecting Overall Job Satisfaction and Turnover Intention," Journal of Management Science, Vol. 2, No. 2 (July-December), Qurtuba University, D.I. Khan Campus, Pakistan

7. Chen, Ying-Chang, Ching Kuo Wang, Wen Cheng, Hwa Hsia Chu, and Ying Chien, 2010, "Structural Investigation of the Relationship between Working Satisfaction and Employee Turnover," The Journal of Human Resource and Adult Learning, Vol. 6, No. 1, June 2010, Viewed on 9 October, 2012, http://hraljournal.com/Page/5\%20\%20Chen,\%20Ying-Chang.pdf

8. Jason H. Hammerberg 2002, "Reasons Given for Employee Turnover in a Full Priced Department Store, A Research Paper," The Graduate School, University of Wisconsin-Stout, Viewed on 10 October, 2012 http://www2.uwstout.edu/content/lib/thesis/2002/2002hammerbergj.pdf

9. Society for Human Resource Management, 2011, "Executive Brief: Differences in Employee Turnover Across Key Industries," December 2011, Viewed on 10 October, 2012, https://www.shrm.org/Research/benchmarks/Documents/Assessing\%20Employee\%20Turnover_FINAL.pd

10. Ahsan Raza Jaffari, Jabran Aziz, Zile Hussain, Nazish Akhter, and Kasif-ur-Rehman, 2011, "Prime and Sub-Prime Factors of Employee Voluntary Turnover in Boom Phase of Industry: Empirical Evidence from Banking Sector of Pakistan," African Journal of Business Management, Vol. 5, No. 15, pp. 6408-6414, August 2011, Viewed on 10 October, 2012, http://www.academicjournals.org/AJBM/PDF/pdf2011/4Aug/Jaffari\%20et\%20al.pdf ISSN 199382332011

11. The Florida Center for Nursing Center, 2012, "The Florida Center for Nursing Center, USA," Viewed on 30 September, 2012, http://www.flcenterfornursing.org

12. The Healthcare Association of New York State, 2010, Allied Health Professional: Growing Demand in times of healthcare change, Results from the 2010 Healthcare Professionals Workforce Survey June 2010, Viewed on 28 September, 2012, http://www.hanys.org/workforce/reports/2010-0622 allied survey results 2010 .pdf

13. The HSM Group, Ltd., 2002, Acute Care Hospital Survey of RN Vacancy and Turnover Rates in 2000, Presented to the American Organization of Nurse Executive, Viewed on 25 September, 2012 http://www.wha.org/workForce/pdf/aone-surveyrnvacancy.pdf

14. Hawai'i AIDS Education and Training Center AIDS Education Project, n.d., Kauai Medical Clinic Physician Retention Plan, John A. Burns School of Medicine Department of Medicine, The University of Hawai'i System, Viewed on 25 September, 2012, http://www.hawaii.edu/hivandaids/Kauai_Medical_Clinic_Physician_Retention_Plan.pdf 


\section{NOTES}

